\title{
HPV16 oncogenes E6 or/and E7 may influence the methylation status of RASSFIA gene promoter region in cervical cancer cell line HT-3
}

\author{
FUFEN YIN $^{1}$, NING WANG ${ }^{2}$, SHANSHAN WANG $^{3}$, FENGSHENG YU $^{2}$, XIN SUN $^{2}$, \\ $\mathrm{XIAO} \mathrm{YU}^{2}, \mathrm{BING} \mathrm{LUO}^{4},{\mathrm{CHENGQUAN} Z \mathrm{ZHAO}^{5} \text { and YANKUI WANG }}^{2}$
}

${ }^{1}$ Department of Obstetrics and Gynecology, Peking University People's Hospital, Beijing 100044;

${ }^{2}$ Department of Obstetrics and Gynecology, Affiliated Hospital of Qingdao University; ${ }^{3}$ Department of Obstetrics and Gynecology, People's Hospital of Huangdao District, Qingdao; ${ }^{4}$ Department of Medical Microbiology, Qingdao University Medical College, Qingdao, Shandong 266000, P.R. China; ${ }^{5}$ Department of Pathology,

Magee-Womens Hospital, University of Pittsburgh Medical Center, Pittsburgh, PA 15213-3180, USA

Received August 4, 2016; Accepted December 27, 2016

DOI: $10.3892 /$ or.2017.5465

\begin{abstract}
Both human papillomavirus (HPV) infection and the aberrant Ras associated domain family gene 1A (RASSF1A) promoter methylation status participate in the pathogenesis of cervical cancer. Some studies suggest that E6, and E7 are involved in the pathogenetic mechanisms of RASSF1A. We mainly explored a possible involvement of HPV16 oncogenes E6 or/and E7 in RASSF1A promoter methylation status and possible roles of RASSF1A gene methylation in cervical cancer. Bisulfite genomic sequencing (BGS) PCR combined with TA clone, methylation-specific PCR (MSP) were used to analyze methylation status of the RASSF1A gene promoter in HPV16/18-positive and HPV-negative cervical cancer cell lines; ectopically expressed HPV16 E6, E7 and E6/E7 cervical cancer cell lines; normal cervical and cervical cancer tissues. The mRNA and protein expression of RASSF1A was detected by RT-PCR and western blotting. Re-expression and downregulated promoter methylation status were detected in the ectopically expressed HPV16 E6 and E7 cervical cancer cell line HT-3. The methylation status and expression of RASSF1A could be downregulated or reactivated by 5-Aza-dc in HT-3 and C33A cells. Additionally, statistics showed significant hypermethylation of RASSF1A in cervical cancer samples compared to that in normal cervical samples $(\mathrm{P}<0.05)$. The false negative rate (FNR) was $6.25 \%$ by $\mathrm{HC} 2$ method, when reconfirmed by HPV detection combining the MY09/11, $\mathrm{GP}^{+} / 6^{+}$and SPF1/2 methods. The ectopic expression of
\end{abstract}

Correspondence to: Dr Yankui Wang, Department of Obstetrics and Gynecology, Affiliated Hospital of Qingdao University, Qingdao, Shandong 266000, P.R. China

E-mail: qdwykpro@163.com

Key words: cervical cancer, tumor-suppressors gene, DNA methylation, RAS association domain family $1 \mathrm{~A}$, human papillomavirus
HPV16 E6 and/or E7 may be involved in aberrant methylation and expression of the RASSF1A gene. RASSF1A gene expression could be regulated by its promoter methylation status. Additionally, the false negativity of the HPV detection may contribute to the uncertain relationship between HPV infection and aberrant RASSF1A promoter methylation.

\section{Introduction}

Cervical cancer is one of malignant tumors which seriously threaten the health of women worldwide (1). The occurrence and development of a variety of cancer including cervical cancer is a multi-gene and factor-involved, multi-stage pathological process (2). HPV is now widely accepted as the essential infectious etiological agent to the development of cervical cancer $(3,4)$. It is well established that the two viral oncoproteins E6 and E7 mediate the oncogenic activities of high-risk human papillomavirus (hrHPV), especially HPV16 and HPV18 (HPV16/18), which have been demonstrated to play critical roles in cervical cancer through different pathways $(5,6)$. HrHPV alone is necessary but insufficient for cervical carcinogenesis; only a small proportion of hrHPV-infected patients develop invasive cervical cancer, and the majority remain subclinical or exhibit only precursor lesions $(7,8)$. This can be accounted for in the involvement of genetic and epigenetic factors either independently or in conjunction with hrHPV infection, therefore, these factors may be implicated in the development of cervical cancer (9). Research has indicated that epigenetic abnormalities, particularly aberrant methylation changes, play causative roles in tumorigenesis $(10,11)$.

The Ras associated domain family gene 1A (RASSF1A) located on 3p21.3, is an established TSG that can regulate cell cycle, apoptosis, and microtubule stability, whose abnormal transcription or expression are closely associated with tumor occurrence and development (12-15). It has been reported that silencing of RASSFIA via DNA methylation rather than mutational events and other genetic changes is a common 
phenomenon occurring in most epithelial tumors, including kidney, bladder, breast, pancreatic, nasopharyngeal and cervical carcinomas (16-22). The aberrant methylation of RASSF1A gene plays important roles in the pathogenesis of cervical cancers, which may be an early event $(9,23)$. Some studies revealed an inverse correlation between RASSF1A methylation and HPV16/18 infection in cervical squamous cell carcinoma (SCC) $(23,24)$, while other studies found no correlation between hrHPV infection and RASSF1A promoter methylation. Thus, further studies are needed to formally establish the relationship between RASSF1A methylation and hrHPV infection.

\section{Materials and methods}

Cell lines and constructs. HPV16/18-positive cervical cancer cell lines HeLa, CaSki, SiHa and HPV-negative cervical cancer cells C33A and HT-3 were obtained from Shanghai Institute for Biological Sciences, Chinese Academy of Sciences Institute of Cell Resource Center (Shanghai, China). In the present study, we established the ectopically expressed HPV16 E6, E7 and E6/E7 cell models of HT-3E6, HT-3E7, HT-3E6/E7, C33AE6, C33AE7 and C33AE6/E7 by transfecting HPV16 E6, E7 and E6/E7 oncogenes with lentivirus vectors into the HPV-negative cervical cancer cell line C33A and HT-3 cells. The C33A-vector (C33A-V) and HT-3 vector (HT-3V) cells were established by transfecting C33A and HT-3 cells with lentivirus vectors that did not code for the HPV16 E6, E7, or E6/E7 proteins as controls. Stable transfectants were selected with $10 \mu \mathrm{g} / \mathrm{ml}$ puromycin for 3 weeks. The transfection efficiency was tested by western blotting. Western blotting showed that the transfected cells successfully expressed the E6, E7, or E6/E7 proteins (Fig. 1).

Cell treatment with 5'-Aza-2-deoxycytidine (5-Aza-CdR). For the demethylation experiments, demethylation was induced with 5-Aza-CdR treatment at a concentration that was able to induce the demethylation of the DNA without killing the cells. CasKi, HT-3 and C33A cells were plated at a density of $8 \times 10^{4}$ cells $/ 25 \mathrm{~cm}^{2}$ flask and treated with various concentrations (5 and $10 \mu \mathrm{M}$ ) of 5-Aza-CdR for $96 \mathrm{~h}$.

Methylation-specific polymerase chain reaction (MSP). bisulphate-modified DNA $(2 \mu \mathrm{l})$ was used as template to amplify in $15 \mu \mathrm{l}$ total reaction mixture which contained $2 \mu \mathrm{l}$ DNA, $1.5 \mu 1$ 10X PCR buffer, $0.75 \mu \mathrm{l}$ each of the forward and reverse primers, $1.2 \mu \mathrm{l}$ dNTPs mixture, $0.15 \mu \mathrm{l}$ Hot Start Taq polymerase (Takara), and 9.4 $\mu \mathrm{l}$ PCR water. Primers for RASSF1A gene promoter amplification was from the literature (25). The primers for the methylated form were 5'-GAG AGCGCGTTTAGTTTCGTTTTC-3' and 5'-ACCCGTAC TTCGCTAACTTTAAAG-3', and the primers for the unmethylated form were 5'- GAGAGTGTGTTTGTTTTGTTTTTG-3' and 5'-CCCATACTTCACTAACTTTAAACC-3'. The PCR involved an initial denaturation at $94^{\circ} \mathrm{C}$ for $10 \mathrm{~min}$, followed by 35 cycles consisting of $94^{\circ} \mathrm{C}$ for $30 \mathrm{sec}$, optimal annealing temperature $56^{\circ} \mathrm{C}$ for $30 \mathrm{sec}, 72^{\circ} \mathrm{C}$ for $30 \mathrm{sec}$, with a final extension at $72^{\circ} \mathrm{C}$ for $10 \mathrm{~min}$. double-distilled water as the blank control. PCR product $(5.0 \mu \mathrm{l})$ was directly loaded on $2 \%$ agarose gels, stained with ethidium bromide, visualized and
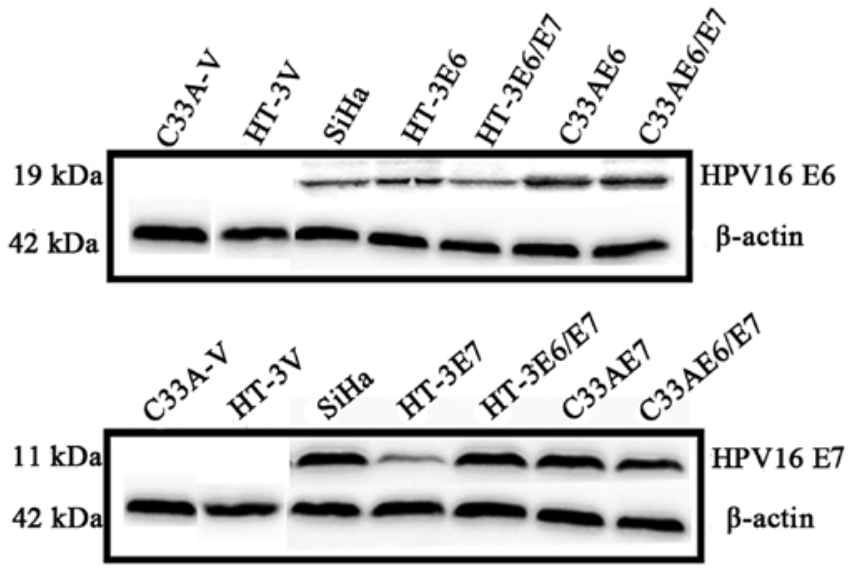

Figure 1. The transfection efficiency of HPV16 E6, E7 or E6/E7 tested by western blotting. SiHa, positive control.

analysis under UV illumination. Each experiment was repeated three times.

DNA extraction and bisulfite genomic sequencing (BGS). The DNA was extracted by using SDS-proteinase K and purified with phenol:chloroform:isoamyl alcohol. A QIAampDNAFFPE tissue kit (Qiagen GmbH, Hilden, Germany) was used for DNA extraction from the paraffin-embedded tumor tissues. The bisulfite conversion of the DNA was performed using an EpiTect Fast DNA Bisulfite kit (Qiagen, Valencia, CA, USA) according to the instruction of the manufacturer. The methylation status of the promoter/exon 1 region of RASSF1A gene in the cervical cancer cells and cervical specimens was analyzed by BGS. BGS strand-specific primers BGSF (GGTTAAGTGTGTTGTTTTAGTAAT, from -271 to -246) and BGSR (CTACCCCTTAACTACCCCTTCC, from +413 to +434) gene were used to amplify a 704-bp region of RASSF1A gene. The purified PCR products were cloned into the pUC18-T vector, and six clones from each sample were randomly selected and sequenced.

RNA extraction and real-time quantitative polymerase chain reaction $(R T-q P C R)$. Total RNA was extracted from cervical cancer cell lines and tissue samples using TRIzol (Invitrogen, Waltham, MA, USA). The cDNAs were synthesized from the templates in presence of reverse transcriptase and oligo(dT) 18 primers in accordance with the manufacturer's instructions. Forward primer (RASSF1A-F: GTGGGAGACACCTGACC TTT) and reverse primer (RASSF1A-R: TGAAGCCTGTGT AAGACCG) were design to generate a $118 \mathrm{bp}$ PCR product at the appropriate annealing temperature. Double distilled water was used as a negative control and the housekeeping gene glyceraldehyde-3-phosphate dehydrogenase (GAPDH) was amplified by primers (5'-GATGACCTTGCCCACAGCCT-3' and 5'-ATCTCTGCCCCCTCTGCTGA-3') to generate a $303 \mathrm{bp}$ PCR product as the internal control. PCR reaction (20 $\mu \mathrm{l}$ ) mixture was pre-denatured at $95^{\circ} \mathrm{C}$ for $2 \mathrm{~min}$, and 35 cycles of $94^{\circ} \mathrm{C}$ for $40 \mathrm{sec}, 55^{\circ} \mathrm{C}$ for $30 \mathrm{sec}$, and $72^{\circ} \mathrm{C}$ for $60 \mathrm{sec}$ was performed with a final extension at $72^{\circ} \mathrm{C}$ for $10 \mathrm{~min}$.

Western blotting. The harvested cells were lysed in RIPA lysis buffer supplemented with protease inhibitor cocktail. 
Table I. Primers and conditions of MY09/11), GP5 $5^{+} 6^{+}$and SPF.

\begin{tabular}{lll}
\hline Primer & \multicolumn{1}{c}{ Sequence } & $\begin{array}{l}\text { Size } \\
\text { (bp) }\end{array}$ \\
\hline MY09/11 & F: 5'-CGTCCMARRGGAWACTGATC-3' & 450 \\
& R: 5'-GCMCAGGGWCATAAYAATGG-3' & \\
GP5'/6+ $^{+}$ & F: 5'-TTTGTTACTGTGGTAGATACTAC-3' & 150 \\
& R: 5'-GAAAATAAACTGTAAATCATATTC-3' & \\
SPF1A & F: 5'-GCiCAGGGiCACAATAATGG-3' & 65 \\
SPF1B & R: 5'-GCiCAGGGiCATAACAATGG-3' & \\
SPF1C & F: 5'-GCiCAGGGiCATAATAATGG-3' & \\
SPF1D & R: 5'-GCiCAAGGiCATAATAATGG-3' & \\
SPF2B-bio F: 5'-GTiGTATCiACAACAGTAACAAA-3' & \\
SPF2D-bio F: 5'-GTiGTATCiACTACAGTAACAAA-3' &
\end{tabular}

F, forward; R, reverse.

Each protein lysate $(30 \mu \mathrm{g})$ was mixed with $5 \mathrm{X}$ SDS-PAGE sample loading buffer, and the mixtures were boiled for $5 \mathrm{~min}$. The boiled mixtures $(50 \mu \mathrm{g})$ were then fractionated on $12 \%$ SDS-PAGE gels and subsequently transferred onto PVDF membranes (Merck Millipore, Billerica, MA, USA). The primary antibodies used for the western blot analyses were anti-RASSF1A and anti- $\beta$-actin. $\beta$-actin was used as a housekeeping protein to normalize the protein loads.

Cervical tissue specimens. This study was approved by the Institutional Review Board (IRB) of the Affiliated Hospital of Qingdao University. All human cervical tissue samples, including 70 HPV16-positive squamous cell carcinoma, $20 \mathrm{HPV}-16$-positive adenocarcinoma, $8 \mathrm{HPV}$-negative cervical cancers, 30 HPV16-positive cervical cancers with PACT (preoperative adjuvant chemotherapy), 30 HPV16-positive normal cervical tissue, were obtained with written informed consent from the donors who underwent primary surgical treatment for cervical tumors or other benign uterine lesions at the Affiliated Hospital of Qingdao University between 2003 and 2015. All cases were reviewed by at least two pathologists to confirm the primary diagnoses.

HPV-DNA detection and genotyping. The detection of HPV DNA was performed in cervical cancer samples by using MY09/11, GP5 ${ }^{+} / 6^{+}$and SPF1/2 methods. Both MY09/11 and $\mathrm{GP}^{+} / 6^{+}$were performed in a final reaction volume of $20 \mu 1$, containing $3 \mu \mathrm{l}$ of the isolated DNA, $2 \mu \mathrm{l}$ of the 10X Buffer, $0.8 \mu 1$ of each deoxynucleoside triphosphate, $0.4 \mu 1$ of forward and reverse primers, and 1.0 units of Taq DNA polymerase (Genebase Bioscience, Guangzhou, China). PCR conditions of MY09/11 were as follows: preheating for $5 \mathrm{~min}$ at $94^{\circ} \mathrm{C}$ was followed by 40 cycles of $130 \mathrm{sec}$ at $94^{\circ} \mathrm{C}, 1 \mathrm{~min}$ at $45^{\circ} \mathrm{C}$, and $1 \mathrm{~min}$ at $72^{\circ} \mathrm{C}$ and a final extension of $7 \mathrm{~min}$ at $72^{\circ} \mathrm{C}$; PCR conditions of $\mathrm{GP}^{+} / 6^{+}$were as follows: preheating for $10 \mathrm{~min}$ at $94^{\circ} \mathrm{C}$ was followed by 40 cycles of $1 \mathrm{~min}$ at $94^{\circ} \mathrm{C}, 2 \mathrm{~min}$ at $40^{\circ} \mathrm{C}$, and $1.5 \mathrm{~min}$ at $72^{\circ} \mathrm{C}$ and a final extension of $7 \mathrm{~min}$ at $72^{\circ} \mathrm{C}$. Each PCR experiment was performed with positive and several negative PCR controls. The final PCR products were separated by electrophoresis in $1.8 \%$ agarose gel. SPF was performed in a final reaction volume of $40 \mu 1$, containing $4 \mu \mathrm{l}$ of the isolated DNA, $4 \mu \mathrm{l}$ of the 10X Buffer, $3.2 \mu \mathrm{l}$ of each deoxynucleoside triphosphate, $0.5 \mu \mathrm{l}$ of forward and reverse primers, and 2.5 units of Taq DNA polymerase (Genebase Bioscience). PCR conditions were as follows: preheating for $1 \mathrm{~min}$ at $94^{\circ} \mathrm{C}$ was followed by 40 cycles of $1 \mathrm{~min}$ at $94^{\circ} \mathrm{C}$, $1 \mathrm{~min}$ at $45^{\circ} \mathrm{C}$, and $1 \mathrm{~min}$ at $72^{\circ} \mathrm{C}$ and a final extension of $5 \mathrm{~min}$ at $72^{\circ} \mathrm{C}$. Each PCR experiment was performed with positive and several negative PCR controls. The products of PCR were then fractionated on $12 \%$ polyacrylamide gel electrophoresis, PAGE gels. As for all methods of HPV-DNA detection and genotyping, see Table I for the detailed primer sequences and size of the product. If results of the three methods were all consistent with each other and negative, the samples were then demonstrated as HPV-negative samples; conversely, if HPV detection of the sample was positive in at least one of the three measures, the samples were defined as positive samples and were further detected by HPV type specific PCR for HPV16 and HPV18 $(26,27)$. Details of PCR are available from the corresponding author.

Statistical analysis. Statistical tests were performed with SPSS version 17.0 (SPSS, Chicago, IL, USA). The correlation between the RASSF1A mRNA expression and the cell lines was analyzed by the analysis of variance (ANOVA), and multiple comparisons were analyzed by the LSD. The correlations between the clinicopathological characteristics and the methylation status of RASSF1A gene were tested using the $\chi^{2}$ test. Differences were considered significant at $\mathrm{P}<0.05$.

\section{Results}

Analysis of RASSF1A methylation and expression in $H P V$-positive and $H P V$-negative cervical cancer cell lines. RASSF1A promoter methylation status was detected in five cervical cancer cell lines by MSP. The results showed that RASSF1A promoter was hypermethylated in two HPV-negative cell lines (C-33A, HT-3), but not in the three HPV-positive cell lines (HeLa, SiHa and Caski) (Fig. 2A). RASSF1A mRNA and protein expression were detected in unmethylated cell lines $\mathrm{HeLa}$, SiHa and CasKi, whereas no RASSFIA expression was detected in the two HPV-negative cell lines HT-3 and C33A with hypermethylated promoters (Fig. 2A). TA clone and BGS results of RASSF1A in these five cell lines showed densely methylated CpG sites C-33A and HT-3 cell lines, while only scattered methylated $\mathrm{CpG}$ sites were detected in $\mathrm{HeLa}$, SiHa and Caski (Fig. 2B). BGS analysis confirmed the MSP results.

Effects of 5-Aza-dc on expression and methylation status of RASSF1A in CasKi, HT-3 and C33A cells. To determine whether methylation status of the RASSF1A gene promoter directly mediates its transcriptional expression, the two cell lines HT-3 and C33A with a complete methylation promoter and CasKi with a complete hypomethylation were treated with 5-Aza-dc of various concentrations (5 and $10 \mu \mathrm{M})$ for $96 \mathrm{~h}$. A gradual restoration of RASSF1A expression was detected in HT- 3 and C33A cells with two different concentrations (5 and $10 \mu \mathrm{M})$ of 5-Aza-dc treatment by real-time quantitative PCR 
A
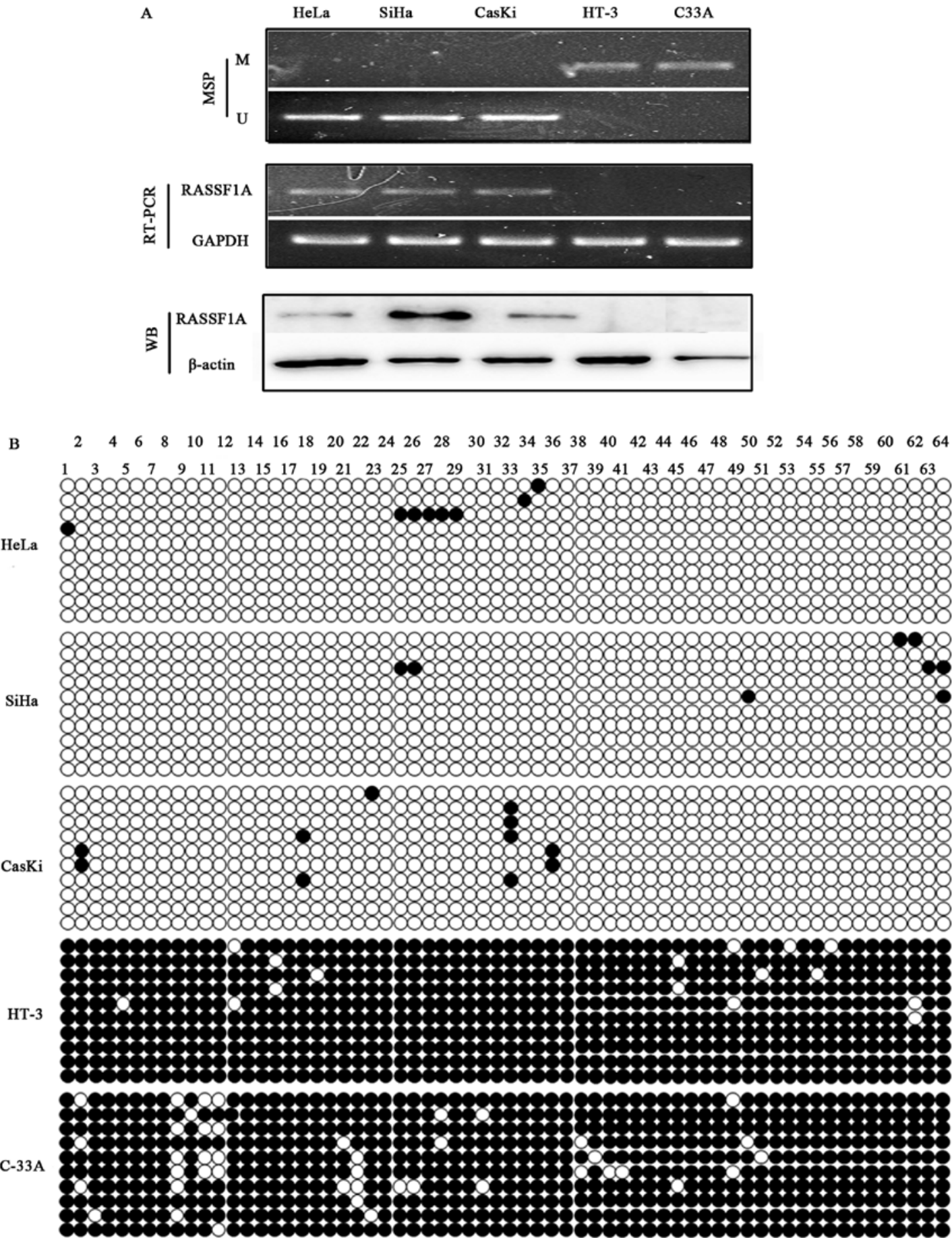

Figure 2. Analysis of RASSF1A methylation and expression in HPV-positive and HPV-negative cervical cancer cell lines. (A) MSP, RT-PCR and western blot results showed that the RASSF1A promoter was hypermethylated in two HPV-negative cervical cancer cell lines (C-33A and HT-3) with a silenced RASSF1A expression, whereas the RASSF1A promoter was hypomethylated in the three HPV-positive cervical cancer cell lines (HeLa, SiHa and CasKi) with a detected RASSF1A gene expression. (B) BGS analyses confirmed MSP results and were consitent with RASSF1A expression trend. $\bullet$, Methylated cytosines; O, unmethylated cytosines.

(Table II) and western blotting (Fig. 3A), concomitant with the demethylation of its promoter detected by BGS (Fig. 3B). No significant changes in the expression and promoter methylation of RASSF1A were detected in CasKi cell before and after being treated with 5 -Aza-dc of different concentrations. As the results in Table II show, after being treated with 5-Aza-dc of various concentrations ( 5 and $10 \mu \mathrm{M})$, RASSF1A mRNA expression was restored to different levels in HT-3 and C33A cell lines. While the expression was not influenced by the demethylating agent 5-aza-dC in CasKi cell line. Thus, in effective concentration range, RASSF1A mRNA expression may be induced by 5 -Aza-CdR concentration dependently in HT-3 and C33A cell lines.

Impact of HPV16 oncogene E6/E7 on methylation status and expression of RASSF1A in HT-3 and C33A cells. BGS results (Fig. 4A) showed that among the HPV16 E6, E7 or E6/E7-transfected cell lines, RASSF1A promoter methylation 

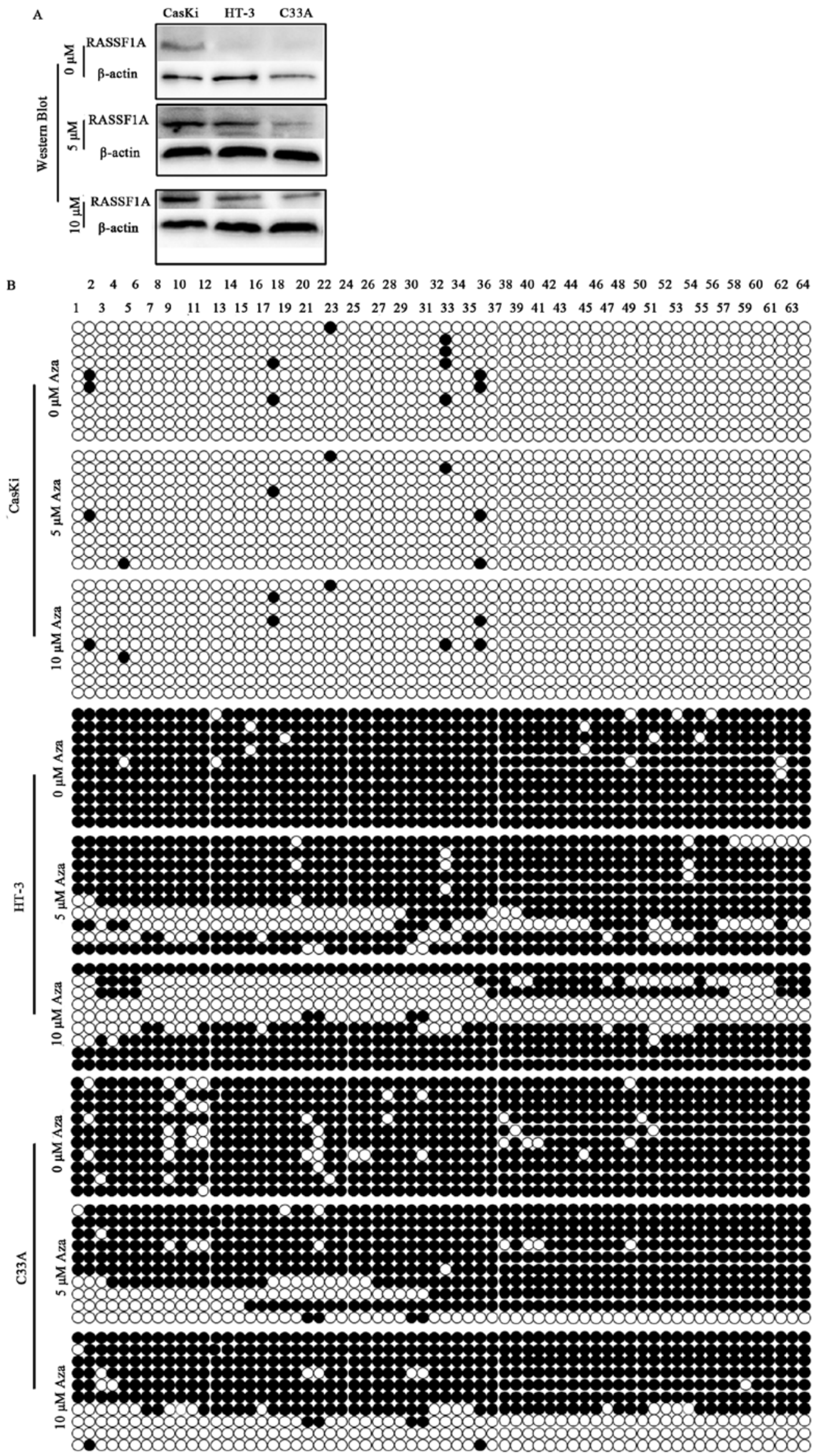

Figure 3. RASSF1A gene expression was regulated by its methylation status. (A) Western blotting revealed RASSF1A gene expression was reactivated by 5-aza-dC in C33A and HT-3 cells, while no significant changes was detected in CasKi cell. (B) Results of BGS showed that demethylating agent 5-aza-dC downregulated RASSF1A promoting methylation status in two HPV-negative cervical cancer cell lines (C33A and HT-3), but no methylation changes was detected in HPV-positive CasKi cell. $\bullet$, Methylated cytosines; $\bigcirc$, unmethylated cytosines. 

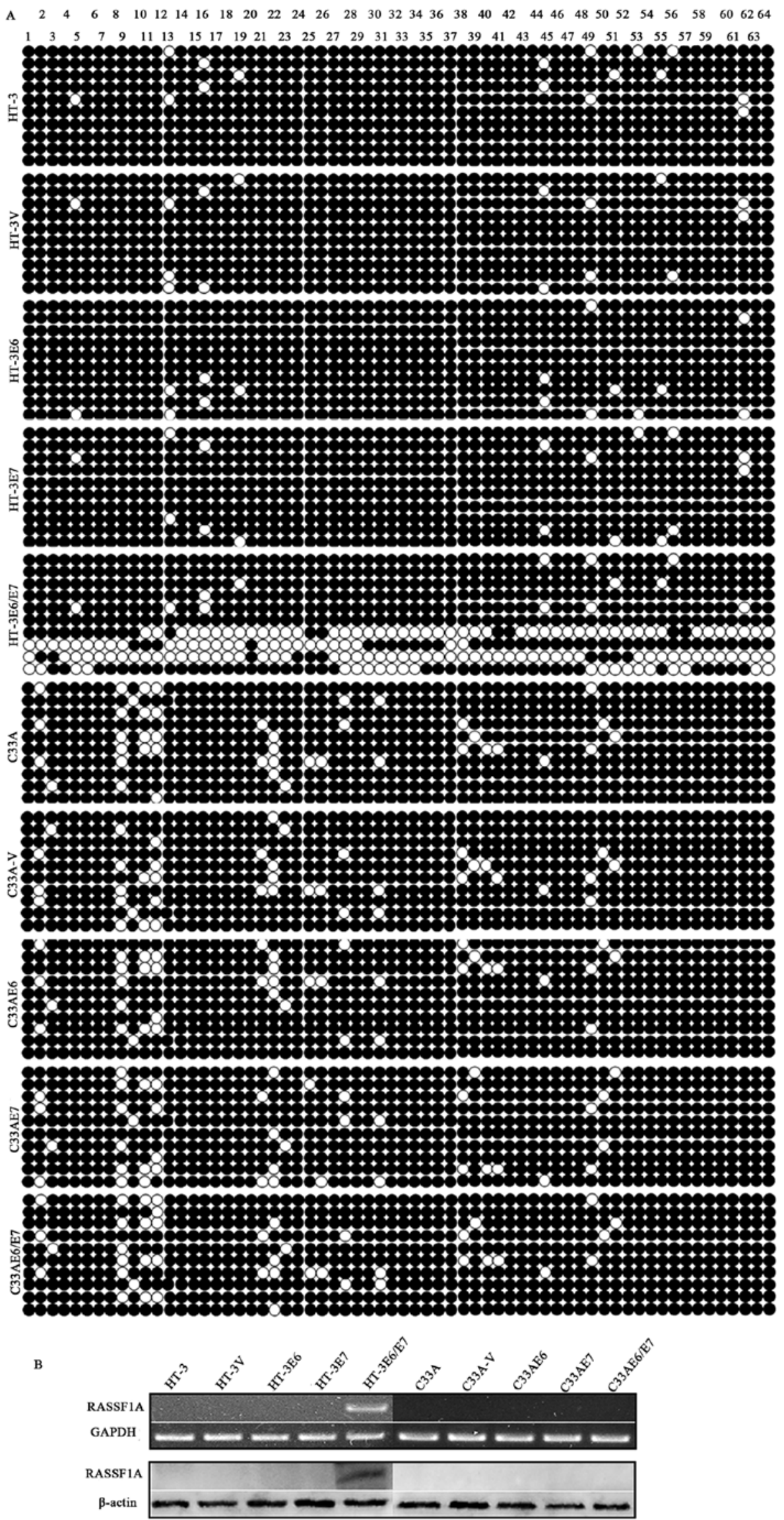

Figure 4. The impact of HPV16 oncogenes E6, E7 and E6/E7 on methylation status and expression of RASSF1A in HT-3 and C33A cells. (A) BGS results showed that among the HPV16 E6, E7 or E6/E7-transfected cell lines, RASSF1A promoter methylation status was relatively downregulated in the HT-3E6/E7 cells but not in other HT-3E6, HT-3E7, HT-3V, C33A-V, C33AE6, C33AE7 and C33AE6/E7 cells compared with the primary HT-3 and C33A cells. (B) The RT-PCR and western blot results were consistent with BGS analyses, showing that RASSF1A gene re-expressed in HT-3E6/E7 cells but not in other HPV16 E6 or/and E7 ectopically expressed cells. •, Methylated cytosines; $\circ$, unmethylated cytosines. 
Table II. The comparison of RASSF1A mRNA expression in three cervical cancer cell lines treated with 5-Aza-dc.

\begin{tabular}{lccrrr}
\hline Cell lines & $0 \mu \mathrm{M}$ & $5 \mu \mathrm{M}$ & $10 \mu \mathrm{M}$ & F-value & P-value \\
\hline CasKi & $0.0407 \pm 0.0056$ & $0.0408 \pm 0.0081$ & $0.0419 \pm 0.0302$ & 1.183 & 0.324 \\
HT-3 & 0 & $0.0108 \pm 0.0036$ & $0.0140 \pm 0.0017$ & 110.792 & 0.000 \\
C-33A & 0 & $0.0115 \pm 0.0011$ & $0.01380 \pm 0.0034$ & 101.558 & 0.000
\end{tabular}

LSD-t test, CasKi cell, $5 \mu \mathrm{M}$ vs. $0 \mu \mathrm{M}, 10 \mu \mathrm{M}$ vs. $0 \mu \mathrm{M}$, and $10 \mu \mathrm{M}$ vs. $5 \mu \mathrm{M}, \mathrm{P}>0.05$; HT-3 and C33A cells, $5 \mu \mathrm{M}$ vs. $0 \mu \mathrm{M}, 10 \mu \mathrm{M}$ vs. $0 \mu \mathrm{M}$, and $10 \mu \mathrm{M}$ vs. $0 \mu \mathrm{M}, \mathrm{P}<0.05$.
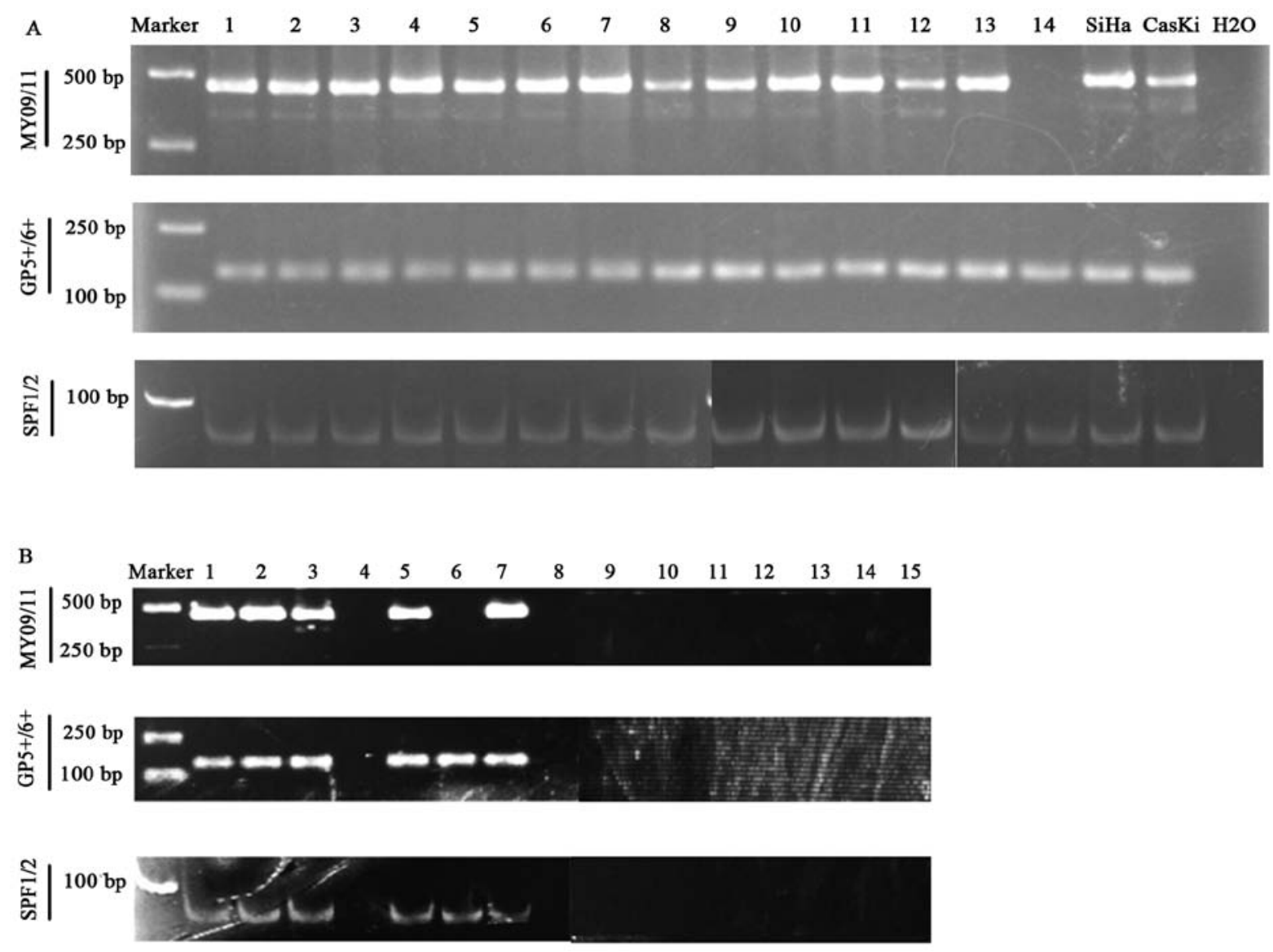

Figure 5. HPV-DNA detection results of cervical cancer samples by MY09/11, GP5 ${ }^{+} / 6^{+}$and SPF1/2 methods. (A) HPV-positive cervical cancer samples $90 / 90$ $(100 \%)$ (previously identified by HC2) were HPV-positive in at least one of the three of MY09/11, $\mathrm{GP}^{+} / 6^{+}$and SPF1/2 methods. SiHa, CasKi: positive control; $\mathrm{H}_{2} \mathrm{O}$ : negative control. (B) Of the $14 \mathrm{HPV}$-negative cervical samples (previously identified by HC2), 8/14 (57.14\%) was confirmed all negative combining MY09/11, GP5 ${ }^{+} / 6^{+}$and SPF1/2 methods, 9/14 (64.29\%) was negative with MY09/11 method, 8/14 (57.14\%) was confirmed negative with $\mathrm{GP}^{+} / 6^{+}$method and $8 / 14(57.14 \%)$ showed negative by simply using SPF1/2 method. $\mathrm{H}_{2} \mathrm{O}$, negative control.

status was relatively downregulated in the HT-3E6/E7 cells but not in the HT-3E6, HT-3E7, HT-3V, C33A-V, C33AE6, C33AE7 and C33AE6/E7 cells compared with the primary HT-3 and C33A cells. The RT-PCR and western blot results (Fig. 4B) revealed that among the HPV16 E6, E7 or E6/E7-transfected cell lines, RASSF1A re-expressed in HT-3E6/E7 cells but not in the HT-3E6, HT-3E7, HT-3V, C33A-V, C33AE6, C33AE7 and C33AE6/E7 cells, which is consistent with the BGS result (Fig. 4A).

HPV-DNA detection results of cervical cancer samples by MY09/11, GP5 $5^{+} / 6^{+}$and SPF1/2 methods. All 90 cases of cervical cancer patients were positive in previous $\mathrm{HC} 2$ test. The HPV DNA was detected in at least one of the MY09/11, $\mathrm{GP}^{+} / 6^{+}$and SPF1/2 methods (Fig. 5A) in all the tumor tissues. Of the $14 \mathrm{HPV}$-negative cervical samples previously identified by HC2 clinically, we retested the HPV DNA infection by combining the MY09/11, GP5 $5^{+} / 6^{+}$and SPF $1 / 2$ methods. The results showed that only $8 / 14$ (57.14\%) was confirmed all negative combining MY09/11, GP5 ${ }^{+} / 6^{+}$and SPF1/2 methods, 9/14 (64.29\%) was negative with MY09/11 method, $8 / 14(57.14 \%)$ was confirmed negative with $\mathrm{GP} 5^{+} / 6^{+}$ and SPF1/2 method, respectively (Fig. 5B). Thus, there was a false negative rate (FNR) of $6.25 \%$ by $\mathrm{HC} 2$ method, when 

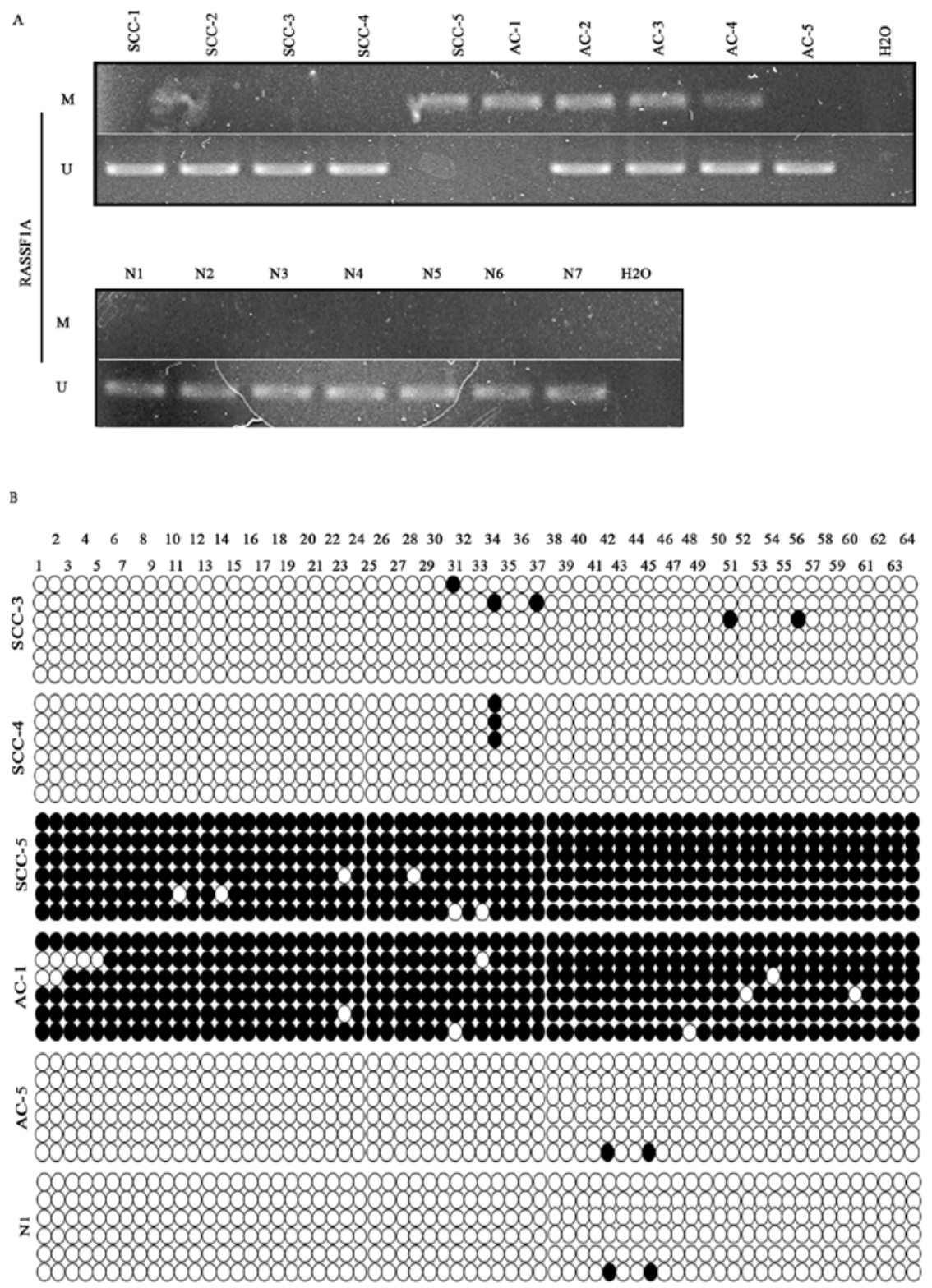

c
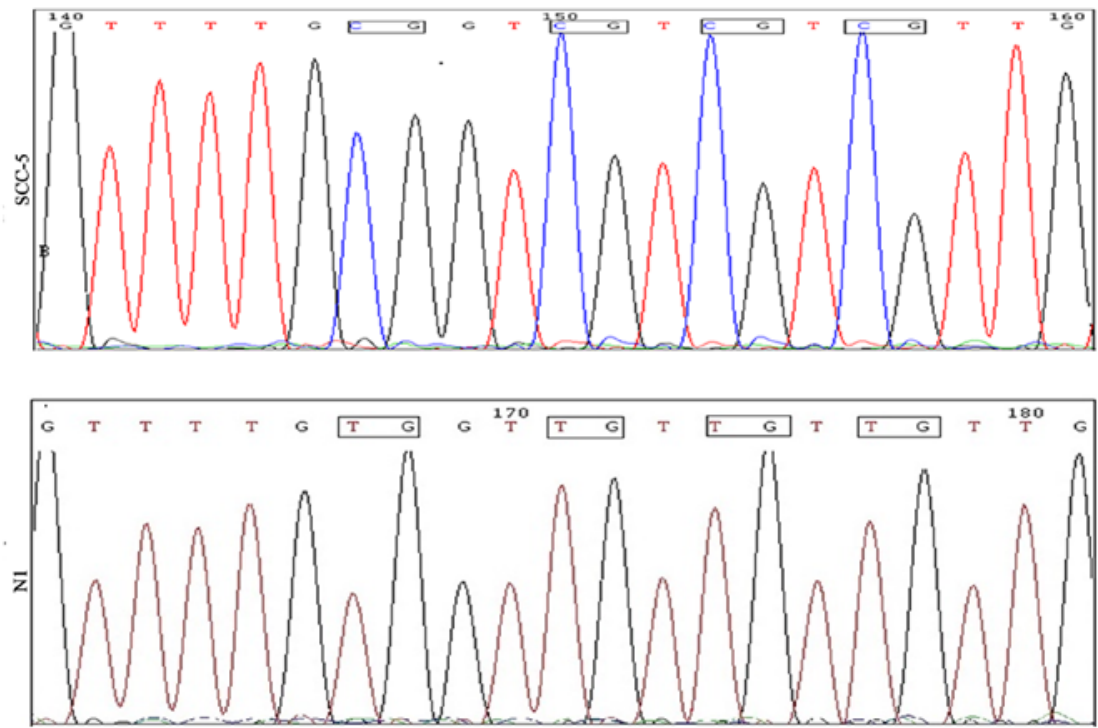

Figure 6. The methylation status of RASSFIA promoter in cervical carcinoma tissue by MSP and BGS. (A) MSP results of some cervical cancer and normal cervical tissues. $\mathrm{H}_{2} \mathrm{O}$, negative control. (B) There are $64 \mathrm{CpG}$ sites in BGS region. SCC, squamous cell carcinoma; AC, adenocarcinoma; N, normal tissue. -, Methylated $\mathrm{CpG}$ site; $\mathrm{O}$, unmethylated $\mathrm{CpG}$ site. $\mathrm{H}_{2} \mathrm{O}$, negative control. (C) DNA sequencing results of RASSFIA gene promoter which analysed by chromas software in squamous cell carcinoma-5 and normal tissue-1. 
Table III. Correlations between RASSF1A promoter methylation and the different clinicopathological features of human cervical cancers.

\begin{tabular}{|c|c|c|c|c|}
\hline \multirow{2}{*}{$\begin{array}{l}\text { Clinicopathological } \\
\text { features }\end{array}$} & \multirow[b]{2}{*}{ No. } & \multicolumn{2}{|c|}{$\begin{array}{l}\text { RASSF1A } \\
\text { methylation }\end{array}$} & \multirow[b]{2}{*}{ P-value } \\
\hline & & + & - & \\
\hline Neoajuvant chemotherapy & 90 & & & \\
\hline No & & 12 & 48 & 0.595 \\
\hline Yes & & 7 & 21 & \\
\hline Tumor size (cm) & 60 & & & \\
\hline$<1$ & & 6 & 34 & 0.903 \\
\hline$\geq 1$ & & 4 & 16 & \\
\hline Smoking & 90 & & & \\
\hline No & & 13 & 71 & 0.938 \\
\hline Yes & & 1 & 5 & \\
\hline Hormone receptors & 60 & & & \\
\hline Negative & & 4 & 21 & 1.000 \\
\hline Positive & & 6 & 29 & \\
\hline $\mathrm{SCC}$ & 70 & & & \\
\hline HPV-positive & & 9 & 56 & 0.032 \\
\hline HPV-negative & & 3 & 2 & \\
\hline $\mathrm{AC}$ & 20 & & & \\
\hline HPV-positive & & 3 & 14 & 1.000 \\
\hline HPV-negative & & 1 & 2 & \\
\hline
\end{tabular}

confirmed HPV detection combining the MY09/11, GP5 ${ }^{+} / 6^{+}$ and SPF1/2 methods.

Clinicopathological significance of RASSF1A promoter methylation status in cervical cancer tissues and normal cervical tissues. MSP analysis indicated RASSF1A hypermethylation was found in 16 of $98(16 \%)$ cancer samples and none in 30 normal cervical samples $\left(\chi^{2}=4.20 ; \mathrm{P}=0.04\right)$. The relations between the methylation status of RASSF1A and the clinicopathological characteristics in the cervical cancer patients were analyzed. The methylation status of RASSF1A promoter was not associated with neoadjuvant chemotherapy, tumor size, smoking or hormone receptors (P>0.05; Table III). Of the 70 SCC, the result showed a statistically reversed relationship between RASSF1A methylation and HPV16 infection $(\mathrm{P}<0.05)$. While of the 20 adenocarcinoma (AC), no significant differences was found between RASSF1A methylation and HPV16 infection. Examples of MSP and BGS results are shown in Fig. 6A and B. DNA sequencing analyzed by chromas software confirmed the results (Fig. 6C).

\section{Discussion}

Specific changes in gene expression in cancer cells could result from epigenetic modifications, such as DNA hypermethylation, which subsequently inactivate some tumor suppressor genes (28). Together with genetic changes, epigenetic modifications can be a driving force behind the stepwise progress of cancer initiation, promotion and progression (29). Despite cervical cancer screening with Pap cytology and HPV testing, cervical cancer remains one of the leading causes of death in women worldwide. HPV is the known etiologic agent for cervical cancer, which can induce epigenetic changes in host cells (30). After HPV infection, normal cervical epithelia must accumulate some important genetic and epigenetic changes which play pivotal roles in gene transcriptional regulation to become an invasive cancer (31). These results indicate that methylation and silence of TSGs induced by HPV may be an important oncogenic mechanism for the development of cervical cancer. It is scientifically significant to explore the relationship between hrHPV infection and TSGs inactivation.

The RASSF1A gene has been demonstrated to be a potential TSG in cervical cancers and its hypermethylation is considered as one of the earliest events in tumorigenesis $(9,23,32,33)$. Both aberrant methylation of the RASSF1A promoter and hrHPV infection are often observed in cervical cancers but their mutual relationship has not been determined $(23,24,34)$. Our current study confirmed that two HPV-negative cervical cancer cell lines had a methylated and silenced RASSF1A promoter (C-33A and HT-3), whereas the other three HPV positive cervical cancer cell lines expressed RASSF1A mRNA (HeLa, SiHa and CaSki), which is consistent with the findings of previous research $(24,35)$. The silence and hypermethylation status of RASSF1A in the two HPV-negative cervical cancer cell lines (C-33A and HT-3) could be reversed by demethylating agent 5 -Aza-dC treatment and the influence was concentration dependent. This is the first demonstration that the RASSF1A mRNA could be reactivated by downregulating its promoter methylation status using demethylating agent 5-Aza-dC, similar to the impact of 5-Aza-dC on RASSF1A gene in esophageal squamous cell carcinoma, synovial sarcoma and melanoma (36-38). Our results showed that the methylation status and expression of RASSF1A gene between the two HPV-negative cervical cancer cell lines (C-33A and HT-3) and three HPV-positive cervical cancer cell lines (HeLa, SiHa and CaSki) were significantly different. Besides, our result showed that the methylation status and expression of RASSF1A gene could be regulated by $5-\mathrm{Aza}-\mathrm{dC}$. The above evidence may imply that there exists a possible interaction between hrHPV infection and RASSF1A methylation in tumorigenesis of cervical cancer.

The oncoproteins E6 and E7 of hrHPV, especially in HPV16/18, have been proved to play critical roles in cervical cancer through different pathways, including inactivating the products of tumor suppressor genes p53 and $\mathrm{Rb}$, respectively $(39,40)$. RASSF1A can induce cell cycle arrest by engaging the $\mathrm{Rb}$ family cell cycle checkpoint and the RASSF1A-induced cell cycle arrest can be relieved by the downstream activators of the G1/S-phase transition (cyclin A and E7) $(13,24,41)$, revealing that E6, E7 may participate in the pathogenetic mechanisms of RASSF1A. In order to explore whether the hrHPV E6 and E7 could be correlated to RASSF1A promoter methylation and expression, we detected the expression and methylation status of RASSF1A in two HPV-negative cervical cancer cell lines HT-3 and C33A before 
and after they were transfected into HPV16 oncogenic genes E6, E7 and E6/E7 with lentivirus vectors.

Our results showed that re-expression and downregulated promoter methylation status were found in the HT-3E6/E7 cells, but not in the HT-3V, C33A-V cells, indicating the ectopic expression of HPV16 E6/E7 may interact with aberrant methylation and expression of the RASSF1A gene without a disturbance of the transfected lentivirus vectors. However, expression and downregulated promoter methylation status of the RASSF1A gene were not found in HT-3E6, HT-3E7, C33AE6, C33AE7 and C33AE6/E7 cells (Fig. 4A and B). In our research, the re-expression and downregulated methylation status of RASSF1A were not detected in HT-3E6, HT-3E7, HT-3V cells. Possible reasons may be the changes of RASSF1A need the co-action of E6 and E7. Likewise, reasons why the re-expression and downregulated promoter methylation status of RASSF1A gene were not found in the C33AE6, C33AE7 and C33AE6/E7 cells may arise from different cell types. Nevertheless, the finding of the downregulated methylation status and re-expression of RASSF1A in HT-3E6/E7 was a phenomenon. This phenomenon is associated with the interaction between HPV16 E6/E7 and RASSF1A. However, further studies need to be focused on understanding the molecular mechanism(s) by which HPV16 E6/E7 impacts RASSF1A methylation status and expression.

Previous studies have showed an inconclusive result of mutual interaction between hrHPV infection and aberrant RASSF1A promoter methylation status. Some studies found an inverse correlation between RASSF1A methylation and hrHPV (type 16/18) infection in SCC $(23,24)$, while other studies detected no correlation between HPV infection and RASSF1A promoter methylation. When exploring the potential relationship between hrHPV infection and RASSF1A promoter methylation in cervical cancers, selection of HPV-positive and HPV-negative cervical cancer samples are required. However, HPV detection could also be false negative $(42,43)$. In our study, we used three PCR primer sets (MY09/11, GP5 ${ }^{+} / 6^{+}$and SPF1/2) to confirm HPV infection status. The statistical analysis indicated there was no false positive in the HPV-positive cervical cancer samples, previously identified by $\mathrm{HC} 2$. While a false negative existed in the HPV detection by HC2 method, showing that only 8/14 (57.14\%) HPV-negative clinical cervical cancer samples (previously identified by $\mathrm{HC} 2$ ) were confirmed all negative combining MY09/11, GP5 ${ }^{+} / 6^{+}$and SPF1/2 methods. The poorly prepared cervical samples for Her2 test may contribute to the uncertain relationship between hrHPV infection and aberrant RASSF1A promoter methylation status to some extent.

Clinicopathological significance of RASSF1A promoter methylation status has been analyzed in various kind of human cancers. Evidence showed that aberrant methylation of RASSF1A promoter were associated with hormone receptor status in breast cancer (44), correlated to responsiveness to chemotherapy in hepatoblastoma patients (45), relevant to cigarette smoking in lung cancer. In cervical cancer, RASSF1A promoter methylation status was demonstrated to be not related to age, the type of cancer, lymph node metastasis, cancer grade, the FIGO stage or HPV genotyping $(13,46)$. Our analysis showed that the methylation status of RASSF1A was not associated with neoadjuvant chemotherapy, tumor size, smoking or hormone receptors (HRs). Consistent with the previous studies $(23,24)$, our result showed a statistically reversed relationship between RASSF1A methylation and HPV infection in SCC $(\mathrm{P}<0.05)$, while no significant differences was found in AC. Moreover, MSP analysis showed a significant hypermethylation RASSF1A in cervical cancer samples compared to normal cervical samples $(\mathrm{P}<0.05)$, revealing RASSF1A may act as a potential TSG in cervical tissues.

\section{Acknowledgements}

This study was supported by the National Nature Science Foundation of China (grant no. 81172480) and Science Foundation for Postdoctoral application project 14 of Qingdao City.

\section{References}

1. Ferlay J, Shin HR, Bray F, Forman D, Mathers C and Parkin DM: Estimates of worldwide burden of cancer in 2008: GLOBOCAN 2008. Int J Cancer 127: 2893-2917, 2010.

2. Feinberg AP and Tycko B: The history of cancer epigenetics. Nat Rev Cancer 4: 143-153, 2004.

3. zur Hausen H: Papillomaviruses in anogenital cancer as a model to understand the role of viruses in human cancers. Cancer Res 49: 4677-4681, 1989.

4. Kitchener HC, Denton K, Soldan K and Crosbie EJ: Developing role of HPV in cervical cancer prevention. BMJ 347: $\mathrm{f4781,} 2013$.

5. Ajiro $M$ and Zheng $Z M$ : $E 6^{\wedge} E 7$, a novel splice isoform protein of human papillomavirus 16, stabilizes viral E6 and E7 oncoproteins via HSP90 and GRP78. MBio 6: e02068-e14, 2015.

6. Narisawa-Saito M and Kiyono T: Basic mechanisms of high-risk human papillomavirus-induced carcinogenesis: Roles of E6 and E7 proteins. Cancer Sci 98: 1505-1511, 2007.

7. Flatley JE, McNeir K, Balasubramani L, Tidy J, Stuart EL, Young TA and Powers HJ: Folate status and aberrant DNA methylation are associated with HPV infection and cervical pathogenesis. Cancer Epidemiol Biomarkers Prev 18: 2782-2789, 2009.

8. Ostör AG: Natural history of cervical intraepithelial neoplasia: A critical review. Int J Gynecol Pathol 12: 186-192, 1993.

9. Neyaz MK, Kumar RS, Hussain S, Naqvi SH, Kohaar I, Thakur N, Kashyap V, Das BC, Husain SA and Bharadwaj M: Effect of aberrant promoter methylation of FHIT and RASSF1A genes on susceptibility to cervical cancer in a North Indian population. Biomarkers 13: 597-606, 2008.

10. Baylin SB: The cancer epigenome: Its origins, contributions to tumorigenesis, and translational implications. Proc Am Thorac Soc 9: 64-65, 2012.

11. Xiong J, Li Y, Huang K, Lu M, Shi H, Ma L, Luo A, Yang S, Lu Z, Zhang J, et al: Association between DAPK1 promoter methylation and cervical cancer: A meta-analysis. PLoS One 9: e107272, 2014.

12. Song MS, Song SJ, Ayad NG, Chang JS, Lee JH, Hong HK, Lee H, Choi N, Kim J, Kim H, et al: The tumour suppressor RASSF1A regulates mitosis by inhibiting the APC-Cdc20 complex. Nat Cell Biol 6: 129-137, 2004.

13. Shivakumar L, Minna J, Sakamaki T, Pestell R and White MA: The RASSF1A tumor suppressor blocks cell cycle progression and inhibits cyclin D1 accumulation. Mol Cell Biol 22: 4309-4318, 2002

14. Agathanggelou A, Cooper WN and Latif F: Role of the Ras-association domain family 1 tumor suppressor gene in human cancers. Cancer Res 65: 3497-3508, 2005.

15. Whang YM, Kim YH, Kim JS and Yoo YD: RASSF1A suppresses the c-Jun-NH2-kinase pathway and inhibits cell cycle progression. Cancer Res 65: 3682-3690, 2005.

16. Peters I, Rehmet K, Wilke N, Kuczyk MA, Hennenlotter J, Eilers T, Machtens S, Jonas U and Serth J: RASSF1A promoter methylation and expression analysis in normal and neoplastic kidney indicates a role in early tumorigenesis. Mol Cancer 6: 49, 2007. 
17. Gao T, Wang S, He B, Pan Y, Song G, Gu L, Chen L, Nie Z, $\mathrm{Xu} \mathrm{Y}$ and $\mathrm{Li} \mathrm{R}$ : The association of RAS association domain family Protein1A (RASSF1A) methylation states and bladder cancer risk: A systematic review and meta-analysis. PLoS One 7: e48300, 2012.

18. Hagrass HA, Pasha HF, Shaheen MA, Abdel Bary EH and Kassem R: Methylation status and protein expression of RASSF1A in breast cancer patients. Mol Biol Rep 41: 57-65, 2014.

19. Malpeli G, Amato E, Dandrea M, Fumagalli C, Debattisti V, Boninsegna L, Pelosi G, Falconi M and Scarpa A: Methylationassociated down-regulation of RASSF1A and up-regulation of RASSF1C in pancreatic endocrine tumors. BMC Cancer 11: 351, 2011.

20. Wu K, Xu XN, Chen Y, Pu XL, Wang BY and Tang XD: RASSF1A gene methylation is associated with nasopharyngeal carcinoma risk in Chinese. Asian Pac J Cancer Prev 16: 2283-2287, 2015.

21. Maliukova AV, Loginov VI, Khodyrev DS, Kadyrova EL, Pronina IV, Ivanova TA, Kiselev FL, Zabarovskiǐ NP and Braga EA: Methylation of the putative tumor suppressor gene, RASSF1A, in primary cervical tumors. Mol Biol (Mosk) 38: 1005-1013, 2004 (In Russian).

22. Pfeifer GP and Dammann R: Methylation of the tumor suppressor gene RASSF1A in human tumors. Biochemistry (Mosc) 70 576-583, 2005

23. Li JY, Huang T, Zhang C, Jiang DJ, Hong QX, Ji HH, Ye M and Duan SW: Association between RASSF1A promoter hypermethylation and oncogenic HPV infection status in invasive cervical cancer: A meta-analysis. Asian Pac J Cancer Prev 16: 5749-5754, 2015.

24. Kuzmin I, Liu L, Dammann R, Geil L, Stanbridge EJ, Wilczynski SP, Lerman MI and Pfeifer GP: Inactivation of RAS association domain family $1 \mathrm{~A}$ gene in cervical carcinomas and the role of human papillomavirus infection. Cancer Res 63 : 1888-1893, 2003

25. Muñoz J, Inda MM, Lázcoz P, Zazpe I, Fan X, Alfaro J, Tuñón T, Rey JA and Castresana JS: Promoter methylation of RASSF1A associates to adult secondary glioblastomas and pediatric glioblastomas. ISRN Neurol 2012: 576578, 2012.

26. Shukla S, Bharti AC, Mahata S, Hussain S, Hedau S, Sharma R, Pillai MR, Krishna S, Chiplunkar S, Tongaonkar H, et al: Application of a multiplex PCR to cervical cells collected by a paper smear for the simultaneous detection of all mucosal human papillomaviruses (HPVs) and typing of high-risk HPV types 16 and 18. J Med Microbiol 59: 1303-1310, 2010.

27. Lee SH, Vigliotti VS, Vigliotti JS and Pappu S: Validation of human papillomavirus genotyping by signature DNA sequence analysis. BMC Clin Pathol 9: 3, 2009.

28. Gal-Yam EN, Saito Y, Egger G and Jones PA: Cancer epigenetics: Modifications, screening, and therapy. Annu Rev Med 59: 267-280, 2008

29. Esteller M: Epigenetics in cancer. N Engl J Med 358: 1148-1159, 2008.

30. Paschos K and Allday MJ: Epigenetic reprogramming of host genes in viral and microbial pathogenesis. Trends Microbiol 18: 439-447, 2010

31. Woodman CB, Collins SI and Young LS: The natural history of cervical HPV infection: Unresolved issues. Nat Rev Cancer 7: 11-22, 2007.

32. Meng W, Huebner A, Shabsigh A, Chakravarti A and Lautenschlaeger T: Combined RASSF1A and RASSF2A promoter methylation analysis as diagnostic biomarker for bladder cancer. Mol Biol Int 2012: 701814, 2012.
33. Senchenko VN, Kisseljova NP, Ivanova TA, Dmitriev AA, Krasnov GS, Kudryavtseva AV, Panasenko GV, Tsitrin EB, Lerman MI, Kisseljov FL, et al: Novel tumor suppressor candidates on chromosome 3 revealed by NotI-microarrays in cervical cancer. Epigenetics 8: 409-420, 2013.

34. Cohen Y, Singer G, Lavie O, Dong SM, Beller U and Sidransky D: The RASSF1A tumor suppressor gene is commonly inactivated in adenocarcinoma of the uterine cervix. Clin Cancer Res 9: 2981-2984, 2003.

35. Yu MY, Tong JH, Chan PK, Lee TL, Chan MW, Chan AW, Lo KW and To KF: Hypermethylation of the tumor suppressor gene RASSFIA and frequent concomitant loss of heterozygosity at 3p21 in cervical cancers. Int J Cancer 105: 204-209, 2003.

36. Guo W, Cui L, Wang C, Guo Y, Shen S, Kuang G and Dong Z: Decreased expression of RASSF1A and up-regulation of RASSF1C is associated with esophageal squamous cell carcinoma. Clin Exp Metastasis 31: 521-533, 2014.

37. Numoto K, Yoshida A, Sugihara S, Kunisada T, Morimoto Y, Yoneda Y, Fujita Y, Nishida K, Ouchida M and Ozaki T: Frequent methylation of RASSF1A in synovial sarcoma and the anti-tumor effects of 5-aza-2'-deoxycytidine against synovial sarcoma cell lines. J Cancer Res Clin Oncol 136: 17-25, 2010.

38. Borden EC: Augmentation of effects of interferon-stimulated genes by reversal of epigenetic silencing: Potential application to melanoma. Cytokine Growth Factor Rev 18: 491-501, 2007.

39. Deshpande R, Mansara P and Kaul-Ghanekar R: Alpha-linolenic acid regulates Cox2/VEGF/MAP kinase pathway and decreases the expression of HPV oncoproteins E6/E7 through restoration of p53 and $\mathrm{Rb}$ expression in human cervical cancer cell lines. Tumour Biol 37: 3295-3305, 2016.

40. Shaikh F, Sanehi P and Rawal R: Molecular screening of compounds to the predicted Protein-Protein Interaction site of Rb1-E7 with p53- E6 in HPV. Bioinformation 8: 607-612, 2012.

41. Farthing AJ and Vousden KH: Functions of human papillomavirus E6 and E7 oncoproteins. Trends Microbiol 2: 170-174, 1994.

42. Naryshkin S and Austin RM: Limitations of widely used high-risk human papillomavirus laboratory-developed testing in cervical cancer screening. Drug Healthc Patient Saf 4: 167-172, 2012.

43. Nocon M, Roll S, Mittendorf T, von der Schulenburg JM and Willich SN: Human papilloma virus (HPV) testing for cervical carcinoma screening. Z Evid Fortbild Qual Gesundhwes 104: 138-142, 2010 (In German)

44. Feng W, Shen L, Wen S, Rosen DG, Jelinek J, Hu X, Huan S, Huang M, Liu J, Sahin AA, et al: Correlation between CpG methylation profiles and hormone receptor status in breast cancers. Breast Cancer Res 9: R57, 2007.

45. Honda S, Haruta M, Sugawara W, Sasaki F, Ohira M, Matsunaga T, Yamaoka H, Horie H, Ohnuma N, Nakagawara A, et al: The methylation status of RASSF1A promoter predicts responsiveness to chemotherapy and eventual cure in hepatoblastoma patients. Int J Cancer 123: 1117-1125, 2008.

46. Lai HC, Lin YW, Chang CC, Wang HC, Chu TW, Yu MH and Chu TY: Hypermethylation of two consecutive tumor suppressor genes, BLU and RASSF1A, located at 3p21.3 in cervical neoplasias. Gynecol Oncol 104: 629-635, 2007. 